\title{
क. Battelle
}

Pacific Northwest Laboratories

Richland, Washington 99352

\section{AEC Research and Development Report}

THE NUCLEAR POWER PLANT IN THE NUCLEAR MATERIAL SAFEGUARDS ACCOUNTING SYSTEM

June 30,1971

in.

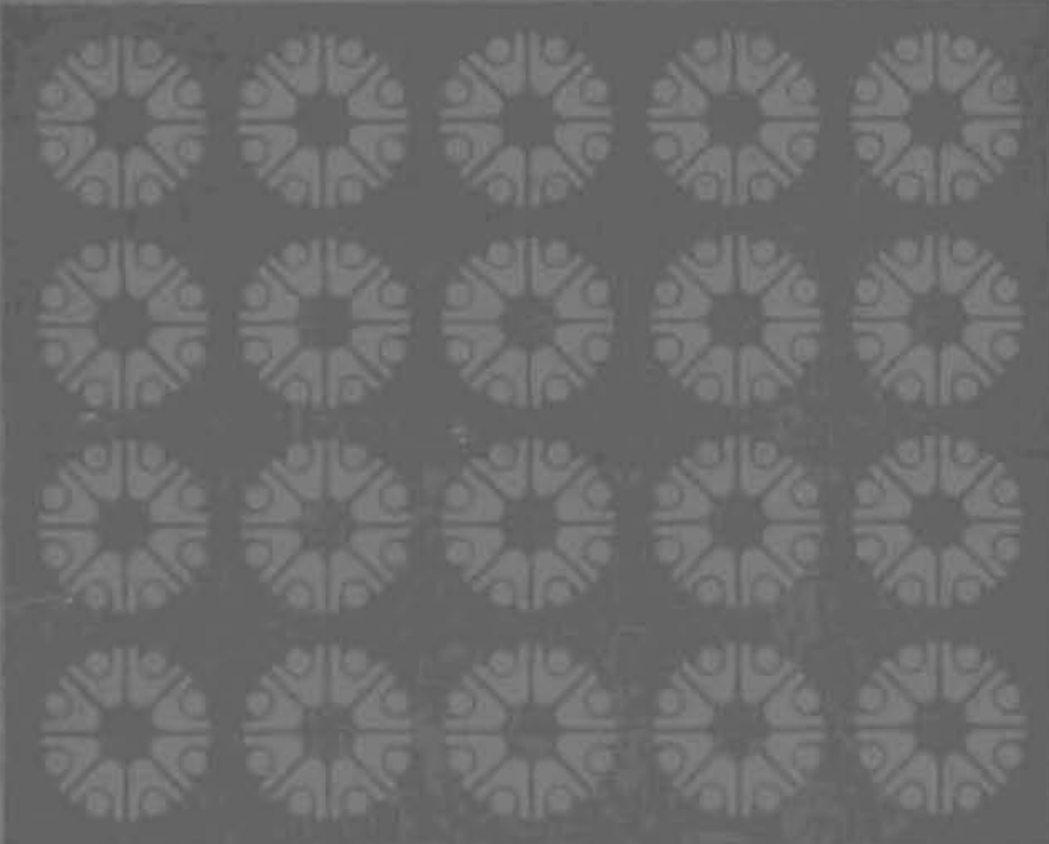


This report was prepared as an account of work sponsored by the United 5tates Covernment. Neither the United States nor the United States Atomic Energy Commission, nor any of their employees, makes any waranty, express or implied, of assumes any legal liability or responsibility for the accuracy. completeness or usefulness of any information, apparatus, product, or process disclosed, of tepresents that is use would not infringe privately-owned rights.

\author{
PACIFIC NORTHWEST LABORATORY \\ operated by \\ BATTELE \\ for the \\ U.S. ATOMIC ENERGY COMMISSION \\ Under Contract AT(45-1)-1830
}

\author{
Printed in the United States of America \\ Availablefrom \\ National Technical information Service \\ US Department of Commerce \\ $52 e 5$ Port Royal Road \\ Springlield, Virginia 22751 \\ Price: Printed Copy \$3.00; Microfiche \$0.95
}

Mos nceusa enen 
THE NUCLEAR POWER PLANT IN THE

NUCLEAR MATERIAL SAFEGUARDS ACCOUNTING SYSTEM

by

R. G. Clark

H. J. Sroboda

V. O. Uotinen

W. C. Wolkenhauer

June 30,1971

Reactor Physics Department

BATTELLE

PACIFIC NORTHWEST LABORATORIES

RICHLAND, WASHINGTON 99352 


\section{TABLE OF CONTENTS}

\section{INTRODUCTION}

PAGE NO.

II. SUMMARY, CONCLUSIONS, AND RECOMMENDATIONS

III. DISCUSSION

A. A Review of Fuel Cycle Analysis For Nuclear Safeguards Considerations

B. Description of The Typical Nuclear Power Plant

C. Power Reactor Operating Data 23

D. Nuclear Materials Safeguards vs. Reactor Mission 3:

E. Opportunities For Diversion 34

IV. ACKNOWLEDGMENT 42

V. REFERENCES 43

VI. BIBL IOGRAPHY 
THE NUCLEAR POWER PLANT IN THE

NUCLEAR MATERIAL SAFEGUARDS ACCOUNTING SYSTEM

\section{INTRODUCTION}

For several years, research has been conducted in the area of safeguards of nuclear material. In general, this effort has concentrated on the chemical processing plant. This is due to the a priori observation that it appears that the chemical processing plant is the most likely point within the nuclear fuel cycle for diversion of nuclear materials.

The basic objective of nuclear materials safeguards research is to study the application of an overall systems analysis of the nuclear material fuel cycle. This effort involves identifying components of the nuclear fuel cycle and doing detailed analysis of each component. The components are fitted together into an overall system and the system can be subjected to a diversion potential analysis.

A typical nuclear material fuel cycle system can include:

- Enrichment facilities

- Fuel fabrication

- Reactor power plant

- Fuel reprocessing plant

- Storage facilities

There are, of course, other components of the nuclear fuel cycle, but the above are the components of major interest from the nuclear safeguards point of view. 
Past research, concentrated on the fuel reprocessing plant, has included:

- An analysis of the capability of a typical material balance accounting system for a chemical processing plant.

- Derivation of cross section ratios suitable for fuel element "fingerprinting"

- Gamma Scanning of spent fuel elements

- Systematic analysis of chemical reprocessing plant data

- Development of fuel element ordering systems for dissolution to improve applicability of chemical plant data to the analysis.

In addition, some work has been done of the effect of reactor operation on possible fuel element "fingerprint." $(1,2,3)$

This document emphasizes the function of the reactor in the nuclear materials safeguards system as opposed to the reprocessing plant. The discussion includes a brief review of the whole fuel cycle and the place of the nuclear reactor in that fuel cycle, a review of systems analysis as applied to safeguards analysis, descriptions of typical nuclear power plants of interest and a review of the data available from power reactors. Then, a discussion is given of the effect of the mission of the reactor on the nuclear materials accounting system. Next the opportunities and relative probabilities of diversion from a nuclear power plant are discussed. Finally, the results are summarized, conclusions drawn, and recommendations for program direction given. These recommendations are based upon items discussed in this report. They constitute identification of areas of technology which have to be understood in order to meet the overall research objective of improving detection of diversion of nuclear material. 


\section{SUMMARY, CONCLUSIONS, AND RECOMMENDATIONS}

A review of the nuclear materials safeguards role of the nuclear power plant in the overall nuclear materials safeguards system has generated several pertinent conclusions. These conclusions are summarized and discussed in this section.

The various types of nuclear power plants common to the U. S. power grid have been reviewed with the intent of identifying plant design features applicable to the safeguards role and determining their degree of uniformity. The following design features have been identified as being of major importance to the nuclear materials safeguards system.

- Fresh fuel storage locations

- Spent fuel storage locations

- Fuel material (oxide)

- Element weights of several hundred pounds

- Element lengths ranging from 14 feet in a thermal reactor to 4 feet in LMFBR's.

In general, the above design features are common to nuclear power plants and of interest to the nuclear materials safeguards system. Beyond that, there is enough uniformity in the design of these features between the various reactor types such that safeguards techniques can be evolved to an acceptable level.

Pertinent parameters and data available from nuclear power plant operation have been identified and discussed relative to anticipated uncertainties. Some of the parameters discussed include:

- Pre-operational data

- Low-power test data 
- Normal operating data

- Instrumentation uncertainties

- Calculational uncertainties

- Correlation uncertainties

Relevant data from nuclear power plant operation is expected to be of increasingly higher quality in the coming years due to:

- Utility acceptance of greater involvement in reactor operation

- The advent of operational codes (ASME, USAEC, etc.) being currently formulated

- Increasing regulatory interest in operational quality control. These factors will tend also to standardize methods of data gathering and correlation. If utilized by the evolving nuclear materials safeguards system, these anticipated improvements can have significant effect on the usefulness of any proposed safeguard technique.

Nuclear power plant instrumentation can be classified as operations type instrumentation. As such, operational instrumentation tends to have relatively large errors associated with it compared to experimental instrumentation. In addition, the basic capability to measure core thermal power is not of sufficient accuracy. This situation can have significant impact upon safeguards techniques developed in the laboratory but applied at the reactor site.

A survey of the current state-of-the-art relative to predictive calculational models shows that significant uncertainties can be currently associated with these models. Although present-day methods of calculating power distributions and burnup are adequate for safe operation, they contain many recognized limitations and inaccuracies. As cores become larger, the predictive problem increases at a faster than linear rate. This is particularly 
true with the introduction of significant quantities of plutonium into the core. Hope for future improvement hinges on the development and introduction of larger and faster digital computers.

Theory/experiment and theory/theory correlations were reviewed in order to clarify the predictive calculational situation, and, in addition, are the subject of a separate document. The error associated with ${ }^{239} \mathrm{Pu}$ content relative to ${ }^{235} \mathrm{U}$ burnup is felt to be of the order of $5 \%$. The error in the ratio of each higher plutonium isotope to its predecessor can be of the order of $10 \%$. Errors associated with power distributions both within the element and across the core, are felt to be of the order of $10 \%$. As a result significant discrepancies have been reported in reprocessing plant data relative to predictive numbers. These errors are deemed undesirably large from the nuclear materials safeguards point of view.

A careful review of the literature supported by calculational efforts indicates that the particular mission assigned to a power reactor can affect the required level of sophistication of the safeguards system associated with a particular plant. For instance, it is relatively difficult to predict the plutonium isotopic content of the core of a load following power plant compared to a base loaded power plant. Recycle facilities have special problems in guarding against diversion of plutonium. Thus, any safeguard system designed should take into account the use of the facility and should be modified according to its particular role.

A systematic review of the opportunities for diversion from the reactor site, either on a clandestine or overt basis, indicates that the probability of direct diversion is low. However, collusion, either inadvertent or permeditated, between reactor operators and fuel reprocessors constitutes a 
potentially dangerous area for diversion.

This review of the function of the reactor within the nuclear materials safeguards system pinpoints a number of required research and development areas. In discussing the effect of the reactor within the materials safeguards system, one obvious area of needed development is to initiate a thorough systematic development of systems analys is techniques. This could include:

- Continuation of the collection of existing data from reprocessed fuel for use in development of a systems analysis model

- Coordination of developmental work connected with the reactor with other areas of systems analysis of the total safeguards system.

One should consider efforts in the development of better mathematical models. Subtopics under this effort could include:

- Theoretical development of burnup models

- Development of more efficient digital coding techniques

- A systematic review of existing capability in burnup calculational technology in order to select the most applicable, presently available set of techniques

- Research into gathering and implementing presently available data for "benchmark" calculations

- Guidance of planned experiments to assure that data collected is useful for calculational development.

- A systematic review of the errors associated with nuclear power instrumentation.

Research and development should continue in areas aimed at nondestructive examination of nuclear power cores. This effort has yielded some of the most useful data to date and is vital to a continuing safeguards system. An addition to this work could be the development of special instrumentation 
for non-destructive analys is of the plutonium content of reactor fuel throughout its residence in the reactor.

Finally, there is a requirement for development of inspection and inventory techniques. This work could also include research into better physical security techniques for the facilities in question. It is particularly important that tools be available so that inspection teams can recognize small diversions which would normally be accounted for by uncertainties. This implies a capability to do extremely accurate error analysis.

The above areas of required research and development have been assigned the following titles and are listed in terms of priority of effort. The area of non-destructive analysis is not included in this priority as it is part of an already on-going program connected with the chemical reprocessing plant. The priority list is:

- Initiate mathematical development of systems analysis model

- Development of inspection and uncertainty analysis techniques

- Development of burnup analysis computational techniques.

The priority assigned to the various areas of development reflects the feedback between the various areas and how they might be most expeditiously developed. It does not reflect their relative importance as they are all considered vital to the program. El imination of a given area would require a re-ordering of priorities.

The recommended initial step in the development of these areas of technology relative to the reactor within the Nuclear Materials Safeguards System would be the determination of the manpower and resources required to initiate this work. 


\section{DISCUSSION}

\section{A. A Review of Systems Analysis For Nuclear Safeguard Considerations}

The nuclear fuel cycle can be defined as the series of events involving nuclear material used as nuclear fuel from the time it is mined or created until the waste is stored. A schematic of the fuel cycle is aiven in Figure III. 1.

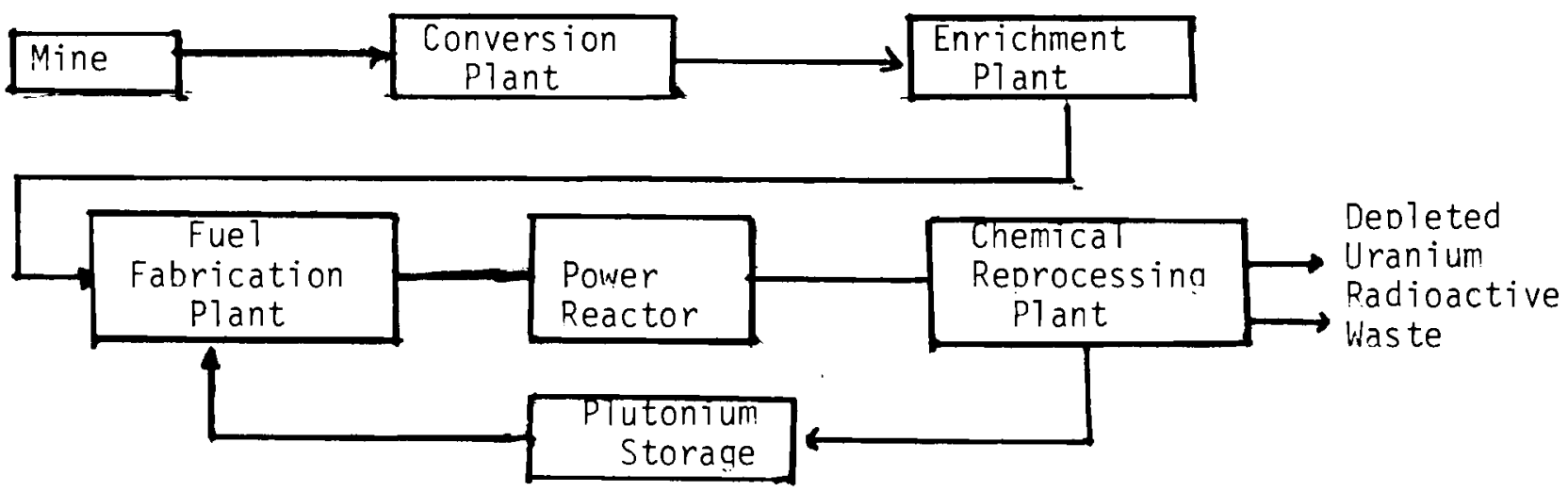

FIGURE III. 1 .

From the standpoint of diversion of nuclear material for weapons purnoses, one particularly wants to account for plutonium. While uranium can be used for weapons purposes, it must be fully enriched in the fissionable isotope ${ }^{235} \mathrm{U}$ to be truly applicable. Typical power reactor uranium is enriched to less than $7 \%$ in ${ }^{235} \mathrm{U}$. Therefore, one can, to a first approximation, concentrate his interest on the fuel fabrication, nower reactor, chemical reprocessing portion of the cycle. 
Fabrication of nuclear fuel elements includes the following activities:

- Procurement of claddina tubing typically of stainless steel or Zirconium alloy

- Receipt and accountability of raw fuel materials

- Manufacture of the nuclear material into ceramic pellets (i.e., $\left.\mathrm{UO}_{2}, \mathrm{PuO}_{2}-\mathrm{UO}_{2}\right)$

- Design and manufacture of grid spacers and end pieces

- Assembly and shipment of the finished fuel bundles.

Plutonium is usually inserted into fuel pins as a mixture of oxides $\left(\mathrm{UO}_{2} / \mathrm{PuO}_{2}\right)$. It can be in particle form or in intimate solid solution with the $\mathrm{UO}_{2}$.

It is possible to divert plutonium from the fuel cycle in certain steps of the fuel fabrication process. This is particularly true if it is clean, relatively unradioactive plutonium. The situation could be particularly tempting because there can be a time lag of years between fuel fabrication and the next physical accounting of the material.

Fuel reprocessing involves dissolution of the fuel elements after their exposure in the power reactor. Steps in this process include:

- Receipt and accountability of the exposed fuel

- Element disassembly

- Cutting of fuer pins

- Chemical stripping of the clad

- Plutonium separation

- Waste separation, handling, and storage.

Because "new" plutonium is separated from the uranium mixture at this point in the cycle and is in a comparatively useful form, the fuel reprocess- 
ing stage of the fuel cycle has received the bulk of the safecuards research interest up to this time. Therefore, it will only receive descriptive attention for the purposes of this work.

During the nuclear reactor portion of the fuel cycle, activities relating to fuel can include:

- Receipt and accountabilitv of new fuel

- Storage of new fue 1

- Core loading of new fuel and recycle fuel

- Core shuffling of exposed fuel

- Discharge of exposed fuel

- Storage of exposed fuel and recycle fuel

- Shipment of exposed fuel

Plutonium is present at the reactor site either as a fabricated fuel or because of its creation due to the U-238 absorption reaction. The forms which it can be found in are:

- In fresh fuel elements as part of the fuel

- In spent fuel elements either as part of the fuel mixture or in "created" form.

The spent fuel bundles are radioactive, and require decay time and/or shielding in order to make handling of them feasible. The fuel elements can weigh several hundred pounds and therefore require the use of slings and cranes in their handling. The fuel pins are welded shut by special welding techniques and diversion of fresh plutonium fuel is therefore difficult, al though substitution of fuel pins is possible.

Systems Analysis, ${ }^{(4)}$ or alternately, simulation for purposes of this work, is a useful method of analyzing overspecified, complex-feedback systems. 
Simulation is characterized by breaking a given system into its components, writing functional descriptions for the components, describing the linkage of components by means of linear equations, and often, using the above mathematical formalism to analyze the system on a digital or analog computer. An error analysis is often included with the overall analysis.

The first step in a systems analysis is to break up any given system into its major components. For the fuel cycle, the major components of a nuclear materials safeguards system have been identified as the fuel fabrication plant, the reactor, plutonium storage, and the chemical fuel reprocessing plant. Linear equations can be written describing the relationships between major components. These equations can describe the time rate of flow of nuclear materials between fuel fabrication, power reactor, plutonium storage, and fuel reprocessing.

It is the practice in Nuclear Materials Safeguards work to refer to the reactor as a "black box". This is to say, one assumes that very little useful safeguards information can be gotten from reactor operations or it is not known what information can be gained. Because of its place in the fuel cycle, one must have an adeauate grasp of reactor processes in order to do meaningful safeguards studies.

The reactor has been considered either unimportant to safeguards analysis and/or too complex for safeguards analys is because:

- Direct measure of its plutonium output is difficult

- Correct calculational models are not sufficiently refined 
- Ability to measure reactor power output is limited

- In general, power reactor instruments are designed for operational rather than experimental work and therefore are not as sensitive as possible

- Power reactors typically do not $h$ ave the experimental nersonnel attached to their staff for gathering reauired safeguards data. Indeed, one could not afford experimental personnel attached to the operation staff of a Dower reactor unless it could be demonstrated that they perform a vitally important or economically rewarding service.

However, a corollary to the systems analys is approach to large engineering systems is that one does not need to know detailed knowledge about a given device within a system. If one has knowledge of the inputs to and outputs from a given device within such a system and some empirical measure of their relationships one, can study the device in the system very effectively. B. Description of the Typical Nuclear Power Plant

\subsection{Introduction}

The various types of nuclear power plants in use within U. S. power grids and other types which can be reasonably anticipated to be in use in the near future include:

- Boiling water reactor

- Pressurized water reactor

- Gas cooled reactor

- Liquid Metal Fast Breeder Reactor Genera? descriptions of each power plant type are given. These descriptions allow for identification of problems and parameters of interest to the 
nuclear safeguards system. Then, a description of a "Composite" reactor is formulated in order to identify components common to the above reactor types and of importance for the nuclear materials safeguards system.

Factors common to the reactor types and of significance to the nuclear materials safeguards systems analys is include:

- Similar fresh fuel storage locations

- Similar spent fuel storage locations

- Fuel in pin/pelletized/oxide form

a Element weights of several hundred pounds

- Element lengths rangina from 12 feet in the thermal reactors to 4 feet for LMFBRS

\subsection{Boiling Water Reactor}

Boiling water reactors ${ }^{(5)}$ have fuel element designs which are different from other reactor designs. Typical fuel elements consist of a $7 \times 7$ square array of .49 fuel pins. The fuel pins have an O.D. of approximately $0.56^{\prime \prime}$ and are on a square pitch of $0.74^{\prime \prime}$. The fuel pins consist of Zircalloy tubing with $0.032^{11}$ wall thickness and are fueled with $\mathrm{UO}_{2}$ cylindrical pellets of $95 \%$ theoretical density. The elements are approximately $12 \mathrm{ft}$. in active length and have several spacer grids along their length to prevent pin bowing and vibration of the pins. The elements are equipped with end pieces. One end piece is a nose piece to fit into the 
grid plate. The other end piece is the upper tie plate with a handle to facilitate transfer of the element. There are three or more different fuel enrichments within each element. The element is enclosed in a flow guide which is a removable, close fitting Zircalloy box covering the length of the element.

Typical fuel elements contain $\mathrm{Gd}_{2} \mathrm{O}_{3}$ burnable poison distributed within the $\mathrm{UO}_{2}$ mixture to provide long term reactivity control. Overall reactor control is accomplished by means of uniform control blades which slide between the elements. These blades consist of $B_{4} C$ pellets in 304 stainless steel clad tubes. The tubes are assembled into a cruciform shape and surrounded by a 304 stainless steel flow guide. The control blades enter the core from the bottom and have at least the active length of the fuel. Additional reactivity control can be achieved by varying the flow of coolent through the reactor core.

A typical 1000 Mk'E core can consist of approximately 750 fuel elements arranged on a square 6 inch pitch with the outer core boundary resembling a cylinder. The core would consist of the fuel elements plus their flow guides, approximately 190 control blades, with each blade bisecting four fuel elements, and grid plate, core structural material, etc. for holding the assembly mechanically rigid. In addition, there can be in-core instrumentation.

Modern boiling light water reactors are direct cycle units. That is, the water pumped through the core is heated, flashed to steam, and sent directly to the turbine. The primary system typically operates at pressures in the range of 1000 psi. A typical cycle consists of feed water entering 
the bottom of the reactor vessel, mixing with recirculated water, and entering the bottom of the reactor core. In the core it is heated to saturated conditions and proceeds by means of a flow deflector plate to the steam separators. The steam proceeds through the steam dryers, leaves the pressure vessel and enters the turbine. From the turbine, the steam proceeds to the condenser and is condensed to water in the shell of the condenser by means of water passing through the condenser tubes. The condensate is pumped through a full flow demineralizer and then by means of feed water heaters and feed pumps back to the inlet of the reactor. In the vessel, separated water proceeds from the steam separators, by means of jet pumps located in the vessel, back to the core for mixture with the feed-water or condensate flow.

Reactor instrumentation can be considered standard except for the presence of in-core fission chambers throughout the core. These instruments, called local power range instruments, are intended to indicate the power distribution of the core over the range of $10 \%$ power to ful1 power. They are periodically calibrated and can be used in conjunction with a data logging on-line computer. Direct computer control of the reactor is not yet a reality.

Secondary systems available include a decay heat system, boron poison injection system, control rod drive auxiliary systems, liquid waste storage systems, off-gas storage system, fuel handling systems, and fuel storage capability.

Typical fuel storage capability is of special interest to the nuclear materials safeguards system. Fuel storage techniques do not vary measurably for water reactors so this description can be used for the water reactor types of interest. 
Fuel storage capability can be divided into two areas. They are:

- Fresh fuel storage

- Spent fuel storage

Spent fuel, for the purposes of this discussion, can be defined as any fuel exposed in the reactor.

Fresh fuel storage generally consists of dry lockable storage vaults. There vaults are lined with neutron absorbina material and are designed to be geometrically subcritical even if flooded. A common design is to place the storage vaults in the concrete shielding surrounding the reactor with access to the vaults being from the reactor pressure vessel head floor.

Spent fuel storage can consist of a large water filled pool adjacent to the pressure vessel. Fuel elements can then be transported to this facility from the reactor by means of a water filled channel. Racks for spent fuel line the edges of the pool in geometrically safe arrays. Fuel storage pools are equipped with criticality alarms, underwater lighting, and convective type cooling facilities.

\subsection{Pressurized Water Reactor}

Pressurized water reactors ${ }^{(6)}$ exhibit some variation in design as there are several manufacturers producina this type of reactor. The differences tend to lie in the areas of:

- Fuel element design

- Reactivity control

- Containment design

In addition, there are variations in system layout between plant types. However, it is possible, by describing a typical plant desianed by a major PWR vendor and by noting variations from this design, to develop an adeauate 
overall description of the Pressurized Water Reactor concept.

A typical PWR fuel element can consist of a $15 \times 15$ square array of fuel pins which results in a nominal 225 pin locations for the element. The elements have grids, top and bottom tie plates, nozzles and carrying handles with the same function but different design geometry relative to the BWR element. Typically, the elements have a single ${ }^{235} \mathrm{U}$ enrichment and have burnable poison in one or more special pins. The fuel is $\mathrm{UO}_{2}$ in pelletized from with a higher ${ }^{235} U$ enrichment than the BWR. The lattice pitch is tighter and rod diameters are smaller. The core contains three different enrichment zones and a 1000 Mwe core can consist of approximately 200 elements. Pin diameters are of the order of $0.4 \mathrm{in}$. and the pin pitch is of the order of $0.56 \mathrm{in}$. Active length is approximately 12 feet and the assembly can weigh in the neighborhood of 1500 lbs. Fuel element pitch is usually of the order of 8.0 inches.

Reactivity control is accomplished by means of:

- Full and partial length control rods

- Soluble poison in the moderator/coolant

- Burnable poison in the fuel.

Typical control rods consist of the cluster of finger-like spines that fit down into the assembly in locations where pins are missing. Thus, there are 204 fuel pins in the 225 pin locations for a typical element. There are then 20 control splines per control cluster. The additional space in the element is used for an instrumentation channel. There can be of the order of 65 contorl clusters for a 1000 Mwe plant. Some of the clusters have partial length absorbers to provide Xenon spatial oscillation control and are continuously 
in the core. The other clusters are generally out of the core and used for safety purposes. Routine reactivity control can be accomplished by changing the soluble poison concentration in the coolant and by appropriate burnable poison distribution. Some PWR plants have cruciform control rods. If this is the case, the fuel elements are appropriately notched to allow the maintenance of the desired tight lattice.

Pressurized water reactors are dual cycle systems. That is, the primary system fluid transmits, by means of a heat exchanger, heat to a secondary system operating at lower pressure. Steam is then formed in the secondary system and sent to the turbine. Typical primary coolant outlet temperatures are of the order of $600^{\circ} \mathrm{F}$ and typical primary system pressure is of the order of $2200 \mathrm{psig}$. There is a pressurizer on the primary coolant loon to maintain this pressure which assures that there is little or no boiling in the primary system. Typical components of the primary system include:

- Reactor vessel

- Steam generator (heat exchanger)

- Coolant pump

- Coolant piping

- Pressurizer and relief tank.

The primary system consists of several coolant loops, the number dependent on reactor power, with each loop containing its own coolant pump and steam generator. For a 1000 Mwe plant, one can expect four coolant loons.

The secondary coolant system consists of the shell side of the steam generators, piping and valves necessary for transport of the steam to the turbine, water quality equipment, the main condensor, condensate pumps, feedwater heaters, and feedwater pumps. The secondary system cycle is therefore comparable to other power plants. 
Like the BWR, one can have waste disposal systems, decay heat systems, radioactive gas disposal system, auxiliary water quality systems, control rod auxiliaries, reactor instrumentation systems and other appropriate auxiliary sys tems.

New and spent fuel storage is accomplished in the pressurized water reactor in a manner similar to that of the boiling water reactor. That is, dry, locked vaults are used for new fuel storage and water-filled pits are used for spent fuel storage. Access to the spent fuel storage pit from the reactor is accomplished by a water-filled fuel transfer canal. The pits are typically equipped with cooling systems. New fuel storage areas can be inside or outside the containment building. Spent fuel storage is typically with in the reactor containment although it can be outside.

\subsection{High Temperature Gas Cooled Reactor}

The following description is for the Ft. St. Vrain ${ }^{(7)}$ reactor. It is the largest gas cooled reactor for commercial use presently being built in the United States. The reactor is a high temperature gas-cooled reactor employing a ${ }^{235} \mathrm{U} /$ thorium fuel cycle, helium cooling and graphite moderation.

The reactor core consists of vertical columns of hexagonal graphite fuel-moderator elements and graphite reflector blocks grouped into a cylindrical array and supported by a graphite core support structure. The core is divided into 37 fuel regions, each consisting of a central fuel element column and six surrounding columns.

Core heat removal is accomplished by the downward flow of the helium coolant through the core and reflector columns. Coolant flowrate through each fuel region is controlled by an orifice mechanism at the region inlet. 
The fuel materials are $93.15 \%$ enriched uranium and fertile thorium in carbide form. Initially, ${ }^{235} U$ comprises the total fissile loading. Later in the fuel cycle, recycle ${ }^{233} \mathrm{U}$ may be included as the fissionable material replacing much of the ${ }^{235} \mathrm{U}$. The uranium and thorium carbide particles are coated with layers of procarbon and silicon carbide and packed in blended beds within the hexagonal graphite elements. The particle coatings provide the prime barrier for fission product retention.

The basic structural material of the core is conventional nuclear grade H-237 graphite machined in the form of hexagonal blocks. These blocks also serve as the moderator and heat transfer medium between fuel and coolant.

The core is designed to maintain a power level of $842 \mathrm{MW}(t)$ in order to achieve a net output of $330 \mathrm{MW}(\mathrm{e})$. The average power density for the steady state power level is $6.3 \mathrm{kw} / 1$ iter. The design plant capacity factor for core reactivity lifetime is $85 \%$ for any one year, but the average load factor over the fuel life is $80 \%$. The helium coolant will be delivered to the steam generator inlet at a total flow rate of about $3.39 \times 10^{6} \mathrm{1b} / \mathrm{hr}$ and a mixed-mean temperature of about $1427^{\circ} \mathrm{F}$.

Helium coolant enters the core at a mixed-mean temperature of about $760^{\circ} \mathrm{F}$ and a pressure of about $700 \mathrm{psia}$ and flows downward through the core. The coolant flow rate through each refueling region is controlled by an orifice mechanism at the region inlet which maintains the exit gas temperature from each region at a uniform $1471^{\circ} \mathrm{F}+50^{\circ},-200^{\circ}$.

The average conversion ratio for the equilibrium cycle is about 0.60 with a $11235 \mathrm{U}$ feed. The average burnup is designed to reach 100,000 MWd per tonne of uranium and thorium in the equilibrium fuel cycle. During the approach to equilibrium the burnup will be somewhat lower. 
The reactor is controlled by 37 pairs of control rods made up of 3.34 in. 0.D. by 2.05 in. I.D. cylindrical absorber bodies containing boron carbide in a graphite matrix sheathed in stainless steel cans. The effective boron load is $0.48 \mathrm{gm} / \mathrm{cm}^{3}$ of compact for the inner 19 and 0.63 $\mathrm{gm} / \mathrm{cm}^{3}$ of compact in the outer 18 control rod pairs. The absorber compacts are to block neutrons up to $10 \mathrm{eV}$.

Heat removal is accomplished by steam generators internal to the concrete pressure vessel. Two 6-module generators are used in this design. As the reactor is modular in concept, larger plants would tend to add loops in a linear manner. Beyond the steam generators, the power plant is essentially of a conventional nature. It is worth nothing that the cycle is somewhat more efficient in terms of electrical generation than the light water reactor cycle.

Because this plant, as presently planned, will not generate significant amounts of plutonium, safeguards efforts for this plant can concentrate on diversion potential for the U-235 feed and U-233 products for the present. However, plutonium enrichment is a reasonable possibility in future cores.

Fuel storage, both fresh and spent, is accomplished in the usual manner. Storage capability is most often placed within the reactor building.

\subsection{Liquid Metal Fast Breeder Reactor}

Liguid Metal Fast Breeder Reactors ${ }^{(8)}$ (LMFBR) are not currently a reality in the power field. However, there is a vigorous engineering program being undertaken by the USAEC and foreign countries to develop this type of reactor and commerical versions can be expected in significant numbers by the 1980 's. Therefore, a viable nuclear materials safeguards system must take into account the pertinent characteristics of this type of plant as they become known. 
As the LMFBR is still in the conceptual and/or preliminary design stage, firm plant descriptions are not possible. However, a brief review of one possible concept is given. This can serve to identify characteristics of importance to the nuclear materials safeguards program.

The power plant consists of a nuclear steam generating system, and the turbine electric generating system. The nuclear power generating system utilizes a sodium cooled FBR fueled with mixed oxides of plutonium and uranium. The reactor is split into a core for power generation and a blanket region for breeding plutonium. Heat transferred to the liquid sodium in the core is used for the generation of $22400 \mathrm{psia} / 900^{\circ} \mathrm{F}$ steam at the turbine. These conditions reflect modern turbine generator technology and therefore higher carnot efficiences than are found in water reactors.

Typical LMFBR's will be built in sizes of 1000 MWe and larger. Early demonstration plants will be of the order of 500 MWe. Design life is considered to be 30 years with and effective availability of 40 years when engineered plant factors are considered.

The reactor is housed in a containment building. A steel pressure vessel is used to house the reactor core and certain supportive equipment. The reactor has an inlet coolant plenum which supplies liquid sodium to the core and blanket region. Sodium flow is vertical to a free surface pool above the core.

The active core is of the order of $4 \mathrm{ft}$. high and $6 \mathrm{ft}$. in diamater. It is controlled by neutron absorbing control rods and by variation of the coolant flow. Fuel elements, containing the oxide in pelletized form, are clad with stainless steel. The fuel elements consist of cylindrical pins $0.25 \mathrm{in.}$ 0.D. There can be of the order of 200 pins per element. A core might be made up of 150 or so elements. 
There are typically two or more primary coolant loops within the reactor. Heat is transferred from the core to the primary loops. It is then transferred by means of heat exchangers, to secondary sodium loops containing steam generators. The steam thus generated is transported to the turbine, then to the condensor where it is condensed back to water, and back to the steam generators by means of condensate pumps, feed water heaters, and feed water pumps. It is, therefore, a three loop design, having primary, secondary, and steam generating systems.

Typical support systems already del ineated for thermal reactors and conventional power plant units are used. The secondary sodium loop is utilized due to radiological and safety considerations.

Fuel handling and storage facilities represent a significant departure from thermal reactors previously discussed. New fuel and recently discharged fuel can be stored within the reactor vessel. Spent fuel which has sufficiently decayed can be transferred from within the vessel to the ex-vessel storage compartment. It can then be transferred from the compartment to a shipping cask. This type of design requires the use of two fairly sophisticated fueling machines. One is used to transfer fuel within the vessel from new fuel storage to the core and from the core to spent fuel storage. A second machine involving the use of rotating plugs is utilized to transfer fuel to and from the reactor vessel. This machine can also be employed to transfer fuel to the shipping cask.

C. Power Reactor Operating Data

1. Codes and Data

Data from reactor operation relevant to the nuclear materials safeguards program are the measures of thermal reactor power versus time, neutron flux 
levels in the reactor core, and the outputs of applicable computer programs which utilize the above data to follow fuel exposure to predict depletion and buildup of heavy metals. ${ }^{(9)}$ To use this data correctly, accurate information on the isotopic distribution and total isotopic content of each fuel unit must be supplied to the utility by the fuel vendor.

The utilities increasing responsibility attendant with nuclear fuel ownership and the substantial investment in their nuclear fuel has warranted correspondingly extensive efforts in fuel mariagement.

Concurrently, the operators are improving and developing standards for use throughout the industry which will improve fuels accounting in the older less well equipped reactors as well as on new units. One such effort has resulted in an ASME Standards Committee with representation from utilities, fuel suppliers, and reactor suppliers, organized in 1965, whose objective has been to develop testing codes. $(10,11,12)$ This is precisely the kind of program required of the nuclear power plant in the safeguards nuclear material accounting system. Several other joint efforts are underway within the industry, supported by AIF and EEI for example, and are contributing to increased capability in nuclear fuels accountability. $(13,14)$

In addition, the USAEC has provided guidelines to the utilities, one of the more recent of which has been Appendix B to 10 CFR 50 - Quality Assurance Criteria for Nuclear Power Plants, which charges the operator with rather extensive quality assurance responsibilities. This will result in increased capability for the utility in their accounting for nuclear fuels. 
The ASME code recommends that the initial total mass of uranium and plutonium of a unit of fuel (one or more fuel assemblies) prior to irradiation shall be determined individually for each fuel assembly from the weight ratio of uranium and plutonium to the total mass of fuel material in the assembly, measured and recorded during the process of manufacture, and that the methods used to determine the mass of uranium in the fuel shall have an uncertainty no greater than $\pm 0.25 \%$ at the $95 \%$ confidence level for a batch of fuel consisting of more than 3000 kilograms of uranium. In addition, for plutonium fuel, the methods shall produce an uncertainty no greater than $\pm 1.0 \%$ at the $95 \%$ confidence level for a batch of fuel consisting of more than $500 \mathrm{~kg}$ of mixed uranium plus plutonium. It appears that fuel vendors are willing to certify routinely, uranium content to less than $\pm 0.25 \%$ and plutonium to less than $\pm 1 \%$.

The standard under consideration seeks to have the calculation method used to determine uranium losses due to depletion and transmutation capable of determining the total mass of uranium at discharge to an uncertainty of no greater than $\pm 0.5 \%$ at the $95 \%$ confidence level.

Increasing attention is being given to evaluation of burnup using added in-core instrumentation and on-line computers which can, with proper software, estimate in great detail fuel burnup. Unsual conditions have existed which have affected the measurement of reactor thermal power and which if not detected would compromise the determination of fuel burnup. The long-term solution to this problem is better design on subsequent units. $(15,16,17)$ 
Instrumentation typically used on power reactors can be classified as operational type instrumentation. That is, it can conform to the following criteria:

- Capable of remote operation for reasonable periods of time wi thout ma intenance

- Capable of operating in hostile environments, i.e., radiation, heat, dust, etc.

- Reasonable unit costs, in terms of capital investment and ma intenance.

The above factors indicate that typical operational instrumentation tends to be durable rather than extremely accurate.

However, certain parameters of interest to the nuclear material safeguards program have to be measured to accuracies beyond the capabilities of standard operational instrumentation. In the absence of special instrumentation designed and installed in power reactors for nuclear safeguards purposes, there are inherent errors in the use of operational instrumentation for the gathering of data which will be used for the nuclear materials safeguards mission.

The nuclear materials safeguards system, if it is to use operational data from power reactors as a means of safeguarding nuclear materials, has to be designed to recognize not only that operational instrumentation is conceived for a different mission than safeguards, but also that advanced techniques used to refine the accuracy of experimental instrumentation are not used in operational instrumentation. 


\section{Physics Behavior}

The physics behavior of a power reactor presents a complex three-dimensional problem. The analysis is complicated by perturbations such as control rods and water gaps, as well as by the effects of themal-hydraulics. The central problem, from a fuel management point-of-view, is that of determining the burnup, i.e., the change in fuel isotopic composition as a function of irradiation.

Fuel data burnup is dependent upon (a) an accurate determination of the integrated thermal power produced by the core, (b) proper assignment of burnup to each fuel assembly, and (c) a proper computer code which uses this information to calculate the depletion of the uranium and the buildup of the plutonium. Calculational methods used for predicting fuel burnup can be classified as 1) cell methods (or point burnup methods) or 2) macroscopic methods. Cell methods are used to evaluate burnup within individual fuel elements, and macroscopic methods are used to perform over-all reactor calculations using the results of cell burnup calculations.

It is in the area of macroscopic reactor calculations that one faces the most severe limitations. The complexity of the physical problem involved is such that an exact solution is beyond the capabilities of today's large computers. One is thus forced to make certain simplifyina assumptions to arrive at a reasonable model for the actual situation. Simplifications come into the model first of all in the basic theory, i.e., in description of the physical processes that are taking place. Further simplifications are made in describing the complex geometrical detail of the reactor core. 
Although present-day methods of calculating power distributions and burnups are considered "adequate" enough to permit the safe operation of reactors, they contain many recognized limitations and inaccuracies. In an assessment of the current status (1968) of reactor calculations made by the USAEC and an industrial task force, it was stated ${ }^{(18)}$ that "nuclear core design is still evolving. Much remains to be learned from reactors not yet operating, regarding prediction and control of the distribution of power between and along the fuel rods making up a core."

In a summary of an IAEA-sponsored panel ${ }^{(9)}$ held in Vienna in 1967 it was stated that "there was general agreement that there is a faster-thanlinear increase in the difficulty of over-all reactor analysis as core size is increased. An additional factor to be considered in burnup calculations, and especially if one is recycling plutonium, is the fact that the reactor physics analysis is complicated if there is a large amount of plutonium in the lattice.

The current state-of-the-art in theory/experiment correlations is fairly well depicted in the Proceedings of a Panel on Fuel Burnup Predictions in Thermal Reactors, ${ }^{(20)}$ held in Vienna in 1967. In the summary section of this panel report, it was pointed out that there was considerable disagreement concerning the absolute magnitude of errors in current predictions. In a discussion of theory/experiment discrepancies one cannot assign the total discrepancy to inaccuracies in theory, but must also take into account the inherent uncertainties in measured quantities. The Vienna panel of 1967 attempted to put their summary of the state-of-the-art of burnup physics on a quantitative basis by commenting on experimental uncertainties as well as on accuracy of predictions. 
Regarding flux and power distributions, a general comment was made (21) that "the precision achievable in estimating many burnup guantities is severely limited by knowledge of the absolute thermal power level of a reactor." Process instrumentation was cited to be typically uncertain to $\sim 4 \%$ of the total themal output of the plant. The accuracy of in-core instrumentation was cited as about $\pm 5 \%$. The precision of power distribution predictions in light water reactors was cited as $3-5 \%$ (r.m.s. deviation), which is within instrumentation error. In general, however, deviations over the whole core fall in an error range of about 10\%, and errors as large as $20 \%$ have been renorted for low flux regions. Furthermore, systematic trends have been noted with region and exposure. These rather large errors are attributed to "inadequate theoretical modeling of the reactor, both as to spatial resolution and physical description."

Regarding isotopic buildup and depletion, it was stated by the panel that "in general, the error in predicting the ratio of ${ }^{239} \mathrm{Pu}$ content to $235 \mathrm{U}$ destruction is about $5 \%$ of its value." As to the prediction of isotopic ratios of various plutonium isotopes, it was stated that "the error in the ratio of each higher plutonium isotope to its predecessor may be $10 \%$.

The agreement between measured power distributions and those calculated using these methods is surprisingly good considering the approximations contained in the methods. These calculations have generally predicted power distributions to within approximately $10 \%$, with the largest discrepancies usually occurring near the reflector or near inserted control rods. 
Regarding theory-experiment correlations of isotopic concentrations and ratios, data were presented on the Dresden and Yankee reactors which showed the following: The mass ratio of plutonium to uranium was underestimated for both reactors - by 5\% for Dresden and by $0.4 \%$ for Yankee; the fissile plutonium fraction was underestimated for both reactors - by $4.5 \%$ for Dresden and by $3.1 \%$ for Yankee. The amount of ${ }^{241} \mathrm{Pu}$ in Dresden was overestimated by $11 \%$. Discrepancies of the same order have been reported by Lacey and Radcliffe ${ }^{(22)}$ of Westinghouse. Reference (21) presents an analysis of Yankee Core I, together with a theory-experiment comparison. The basic analytical tool used in this study was the TURBO ${ }^{*}$ code, a two-dimensional, few-group, diffusion-theory depletion code. 


\section{Nuclear Materials Safeguards vs. Reactor Mission}

1. Introduction

Nuclear power plants can have several different missions. (23) Typical missions include:

- Load following - U-235 fuel

- Load following - recycle (Pu) fuel

- Base Load - U-235 fue1

- Base Load - recycle (Pu) fuel

Classification of the power plant according to its missions allows one to determine the type and complexity of safeguard system required.

The existence of distinct roles which can be assigned to nuclear power plants within the utility system indicates that distinct levels of safeguards protection should be assigned to a reactor based on its production role. Levels and types of nuclear safeguards adequate and necessary for certain plants can be inadequate or unnecessary for other plants.

The load following reactor will have to report detailed operational and design information in order that one can adequately monitor its nuclear material inventory. Base loaded reactors can be monitored with the reporting of fewer operational and design parameters. Recycle facilities, because of the presence of plutonium in all stages of reactor cycle, constitute special security problems for the nuclear material safeguards system.

\section{Load Following}

A power reactor whose operation is classed as load following is one in which the power level of the unit follows the system power demand. Typically, the load following units in the utility system are the older, more 
expensive, units to operate. In certain instances, they may be the most flexible units. This criteria tends to contradict the previous one as the most flexible units tend to be the newest units. In general, however, load following units would tend to have a smaller power rating relative to the average unit size in the utility system. From a nuclear materials safeguards standpoint, the importance of load following is that the detailed isotopic composition of the reactor core with burnup is much more difficult to predict for a load following unit than are the isotopics of the core of a constant power level reactor.

One controls a nuclear power plant by changing the reaction rate for thermal neutrons. This can be done by either

- absorbing therma 1 neutrons

- changing the energy spectrum.

Examples of control by absorbing thermal neutrons include the use of burnable poisons, control rods and soluble poisons. Methods of changing the energy spectrum include changes in void concentrations, changes in feed water flow rate, and so forth. A11 control methods are based on varying the thermal neutron reaction rate.

Consider then, the situation for a reactor whose power level might change periodically during a given day. The ratio of the epithermal reaction rate to the thermal reaction rate would change markedly with the utility system power demand. The ratio of isotopic inventories dependent on epithermal neutron reaction rates as compared to isotopic 
inventories dependent upon thermal reaction rates would change with changing power level.

Calculations performed have shown the following results. Power level has little relative effect of the total uranium or plutonium concentration. However, it does effect the relative amounts of the higher plutonium isotopes carried in the core. That is, the concentration of ${ }^{240} \mathrm{Pu},{ }^{241} \mathrm{Pu}$ and ${ }^{242} \mathrm{Pu}$ are dependent on the mission of the reactor.

This means that if a reactor is used for a load following mission, one must have a fair amount of information in order to predict its isotopic inventory with time relative to the concentration of ${ }^{240} \mathrm{Pu},{ }^{241} \mathrm{Pu}$ and ${ }^{242} \mathrm{Pu}$. The type of information required in order to perform calculations to accurately predict these isotopic concentrations inciude:

- Power lever changes

- Control rod patterns

- Solubie poison concentrations and changes with time

- Burnabie poison distribution

- Core coolant flow rates

\section{Base Load}

A base loaded reactor is one which is taken to full power and kept there for the duration of the run. Base loaded power reactors tend to be

- The newer larger units

- The least flexible units

- The most economical units

As in the load following reactors, the power level is controlled by controlling the thermal neutron reaction rate. However, with constant power 
level, the thermal neutron reaction rate is held constant with local exceptions to control xenon oscillations. Even these oscillations have relatively long (i.e., 8 hour) periods and do not require rapid, strong adjustment of the reaction rate.

Therefore, an accurate prediction of the isotopic core inventory can be made with a considerably simpler mathematical model relative to the load following reactor.

4. Recycle Facility

A nuclear power plant used as a plutonium recycle facility has nuclear materials safequards problems unique to its mission. Because the reactor is fueled partially or in total with plutonium, the opportunities for diversions, both clandestine and overt, are present throughout the residency of the core at the site. This situation does not exist to the same degree in uranium fueled facilities.

Accounting procedures developed for use in uranium fueled facilities would perhaps be adequate safeguards protection for plutonium fueled facilities in the case of cladestine diversion. More frequent inventory checks would be in order and more frequent use of fuel element inventory measuring instrumentation, (i.e., gamma scanning) might be in order. The overt diversion problem in plutonium facilities may require the assignment of guards or alarm devices to the facility while it is used for the recycle role.

\section{E. Opportunities for Diversion}

1. Introduction

The opportunities for diversion of nuclear material during the period of residence of the fuel at the reactor facility is reviewed and discussed 
in this section. The discussion is given relative to:

- Unirradiated fuel shipment

- Unirradiated fuel storage

- Reload

- Irradiated fuel storage

- Irradiated fuel shipment

Emphasis is placed on the diversion of plutonium bearing nuclear materials due to their higher potential for weapons application. Plutonium can be readily separated from uranium and can be separated into a form immediately applicable for nuclear weapons applications. Uranium used in nuclear power plants is typically lightly enriched in the fissionable isotope U-235 and is therefore much less attractive for diversion.

For the purposes of this work, diversion of nuclear material can be classified into one of three areas. These are:

- Clandestine diversion - this form of diversion can be characterized as concealed diversion.

- Overt diversion - this form of diversion can be classified as diversion without concealment and possibly with the use of physical force.

- Implied diversion - there is a third area which can be classified as implied diversion. This is really a potential for diversion caused b by uncertainties in measurements. It represents that portion of material unaccounted for due to system holdups, random uncertainties and systematic uncertainties.

In general, this discussion of potential diversion is related to the first two categories. While implied diversion is discussed when error analysis techniques are used, implied diversion is generally covered in other work concerned more with the material unaccounted for approach. 
The nuclear reactor is the portionof the cycle in which the plutonium is created. As is shown in other sections of this report, calculational models available for prediction of the plutonium content have certain appreciable sources of error inherent in their formulation. Beyond this there are significant errors in measured parameters connected with the power plant which are inputs to the calculational model. An example of one of these parameters is the reactor power level. Therefore, there currently exist significant discrepancies in the plutonium amount predictions associated with spent fuel shipped to the processor. This siutation allows for clandestine or implied diversion of plutonium.

In one instance, if the plutonium concentration in the fuel is underpredicted, one could divert plutonium during reprocessing with no perturbation of the written record from the reactor. In another instance, the wide error bands on the plutonium prediction allow for the possibility of collusion for diversion purposes between reactor personnel and reprecessing personnel. Thus, while opportunities for direct diversion are relatively small in connection with the nuclear reactor portion of the cycle, the current inability to accurately predict plutonium buildup can encourage opportunities for diversion elsewhere in the cycle. Therefore, the reactor must be included in the safeguards system and significant research and development on plutonium predictive capability must be undertaken.

In reviewing the opportunities for diversions of nuclear material from the power reactor portion of the nuclear fuel cycle, one finds a somewhat paradoxical situation. It is somewhat easier to divert fresh fuel than spent fuel. However, the spent fuel is a much more attractive candidate for 
diversion due to its plutonium content and is more difficult to check controlling measures. An exception to this is fresh fuel containing plutonium. To summarize:

- Diversion of fresh uranium fuel during shipment, storage or loading, either by overt or clandestine techniques is not attractive because of the lack of incentive.

- Diversion of snent uranium fuel during unloading, storage, or shipment is, either by overt or clandestine techniques, improbable because of radiation and other handling problems.

- Diversion of plutonium bearing fuel, either by overt or clandestine methods, is possible. If done, in all probability it would take place before exposure in the reactor. The incentive is valid and handling problems are relatively minor in nature. This possibility has to be guarded against.

However, although in review, diversion from the nuclear reactor portion of the cycle seems unlikely, the nuclear reactor does play an important role in the safeguards system.

\section{Unirradiated Fuel}

Opportunities exist for overt diversion of unirradiated nuclear fuel elements during shipment. Typically, the elements are shipped in wooden crates, each shipment consisting of a subcritical batch of three or so elements. and the shipment takes place by means of a light truck. These trucks maintain regular and recorded schedules and are driven along main truck routes. 
3. Unirradiated Fuel Storage

Standard practice upon receipt of fresh fuel is to:

- Visually inspect the fuel for damage in transit

- Wipe the fuel for health physics tests

- Store the fuel in dry, locked, permanent storage vaults.

Overt diversion of fresh nuclear fuel elements is possible. Guards are typically not stationed at nuclear reactors. The swing and graveyard operating crews can be quite small. Typical construction of the storage vaults are such that they could be readily forced open. Perhaps the greatest difficulty would be in handling the elements due to the fact that they weigh several hundred pounds. There are, however, overhead cranes available for this purpose. The radiation hazard associated with fresh, undamaged fuel elements is minimal.

Clandestine diversion of nuclear fuel during cold storage is extremely difficult. Multiple records are kept both at the point of shipment and at the reception point. Therefore, record falsification necessary for diversion would require the collusion of several individuals from separate organizations. Substitution, however, does offer some promise as a means of diverting whole or partial fuel elements, due to the fact that routine tests are not performed on the fuel during or after shipment to determine its contents. Explicit inventory of the fuel pellet material is difficult due to the design of the fuel elements. 
4. At Reload

Standard practice at reload time is to transfer new fuel from the storage area to the core by means of the refueling bridge. After refueling, the pressure vessel head is restored to the system in preparation for the next power run. These operations are carried out by a refueling crew under the direction of a shift supervisor. A fuel accountability representative of the reactor operator is present, and in addition, a representative of the USAEC and the fuel manufacturer are often in residence. The opportunities for overt or clandestine diversion of nuclear fuel during these events is, for practical purposes, non-existent.

\section{Irradiated Storage}

After exposure in the reactor, fuel elements have appreciable inventories of plutonium. Although this plutonium is not necessarily of the best isotopic composition for weapons applications, due to its high content of ${ }^{240} \mathrm{Pu},{ }^{241} \mathrm{Pu}$ and ${ }^{242} \mathrm{Pu}$, it is nevertheless adequate for the production of nuclear warheads. Therefore, at the point of unloading of the exposed fuel from the power reactor, there exists for the first time, material ripe for diversion. Plutonium that has been used for recycle fuel is accounted for very exactly. However, plutonium created in the reactor can only be accounted for at this stage by a calculation or by external (e.g., gamma ray) measurement. Therefore, from the point of creation until measurement at the reprocessing plant, the amount of plutonium is a relatively unknown quantity. On the other hand, fuel elements exposed in the reactor are highly radioactive and can only be handled with the use of special shielding and special procedures. This tends to lessen diversion possibilities, but makes detection of diversion more difficult. The fuel is typically stored in "spent fuel" water pools at the reactor site for some time before shipment. This allows for decay of the fission products within the fuel elements which facilitates their later handling. Spent fuel pool are large water filled, concrete tanks 
with stainless steel linears. They have fuel racks for the storage of spent fuel. Typically, they are covered with light metal or wood covers to alleviate humidity problems as the pools are placed next to the pressure vessel within the containment building. The fuel is removed from the reactor and placed in the pool by means of the loading bridge. The pool is equipped with a cooling system sufficient to handle the full load of spent fuel in the pool.

Due to the radiation hazard, diversion of nuclear material during the hot storage phase either on an overt or clandestine basis, is deemed improbable.

6. Hot Shipping

After a period of several months cooling, the radiation level of spent fuel is such as to allow its shipment to the reprocessing plant. The shipping is accomplished by means of a large, lead shielded, water cooled, cask capable of holding several elements. The cask can weigh ten to twenty tons. Typically, the cask is loaded by drawing it up into the reactor building and immersing it in the spent fuel pool. The fuel elements are then drawn up into the cask by means of the refueling bridge. The cask is sealed, taken out of the reactor building by means of the building crane, transferred to a dolly on rails for movement to the loading dock, and then transferred to a railroad car for shipment to the reprocessing plant.

Loading of the cask is done by a loading crew under the supervision of a shift supervisor. It is accomplished in the presence of a fuel accountability representative of the operating utility. USAEC compliance personnel and representatives of the reprocessor or fuel manufacturer might be present during the operation. 
After transfer to the railroad car, the cask is typically not guarded or accompanied by operator or USAEC representative on its journey to the reprocessing plant. However, due to the cask size, the irradiation hazard, and public scrutiny, diversion, either of a clandestine or overt nature during hot shipment, is deemed improbable. 


\section{ACKNOWLEDGMENT}

The authors would like to express their appreciation to Dr. L.C. Schmid, Mr. R. C. Liikala and Dr. N. E. Carter for their review of the total document. 


\section{REFERENCES}

1. D. E. Christensen and R. A. Schneider, "Consistency Evaluation of Accountability Data for a Chemical Processing Plant," BNWL-CC-2346, (Nov. 1969).

2. "Evaluation of Minor Isotope Safeguard Techniques (MIST) in Reactor Fuel Reprocessing - Field Test FT-62," Prepared by Field Operations, Weapons Evaluation and Control Bureau, U.S. Arms Control and Disarmament Agency (Jan. 27, 1969).

3. D. E. Christensen, R. P. Matsen, R. A. Schneider, and W.C. Wolkenhauer, "The Safeguards Value of Chemical Plant Accountability Data Related to Burnup - Yankee Cores V and VI," IAEA Symposium on Progress in Safeguards Techniques, Karlsruhe, Germany (July 1970).

4. M. A. Schultz, Control of Modern Reactors and Power Plants, McGraw-Hil1 (1961) Chapter 3.

5. Safety Analysis Report, Section 3, Enrico Fermi Atomic Power Plant, the staff of the Detroit Edison Col (1969).

6. Safety Analysis Report, Section 3, Trojan Nuclear Plant, the staff of Portland General Electric Co. (1969).

7. Safety Analysis Report, Section 3, Ft. St. Vrain Nuclear Station, the staff of Public Service Company of Colorado, (1969).

8. 1,000 Mwe LMFBR Follow on Study - Task 3 RPT., AI-AEC-12792 (1969).

9. Operating Manual - LaCrosse Boiling Water Reactor, Allis Chalmers Co., (1966).

10. Nuclear Steam Supply Systems Performance Test Codes, American Society of Mechanical Engineers, 345 East 47 th St., New York, N. Y.

PTC 32.1 (1969).

11. Asme Power Test Code for Nuclear Reactor Fuel Performance, PTC 32.2 (in Publication).

12. Guidance for Evaluation of Measurement Uncertainty in Performance Tests of Steam Turbines, PTC 6 Report (1969).

13. G. C. Andogninni, Private Communication.

14. G. J. Walke, Private Communication. 
REFERENCES (CONTD)

15. J. W. Kutcher and R. I. Smith, Power Tests with the $\mathrm{UO}_{2}-2 \mathrm{wt} \% \mathrm{PuO}_{2}$ Batch Core in the PRTR, BNWL-1383, (1970).

16. J. E. Salecki, Steam and Pressure Requirements for 800 MWe at $N$ Reactor WPPSS Complex. DUN 6948 (1970).

17. J. J. Loving and R. J. North, Reactor Core Measurements at ConnecticutYankee and Zorita. Westinghouse Nuclear Energy Systems, Penn Center Site, Pittsburgh, $\mathrm{Pa}$.

18. Current Status and Future Technical and Economic Potential of Light Water Reactors, WASH-1082, p. 5-16, Jackson and Moreland Division of United Engineers and Constructors Inc., and S. M. Stroller Associates, Under the Direction of DRDT, March 1968).

19. "Fuel Burnup Predictions in Thermal Reactors," Proc. of An IAEA Panel, Vienna, STI/PUB/172, p. 229, 1968.

20. Ibid. p. 172

21. Ibid. p. 236

22. P. G. Lacey and R. E. Radcliffe, "Diffusion Theory Depletion Analysis of the Yankee Core," WCAP-6077, Westinghouse Atomic Power Division (1967).

23. D. E. Christensen et a1., Significant Properties of Chemical Reprocessing Plant Measurements Relating to Burnup - Yankee Cores I through IV. (1970). 
VI. BIBLIOGRAPHY

1. 0. J. Ortega, et al, San Onafre Experience with Apparent Power Mismatch and Reactor Coolant Temoerature Anomalies. So. Calif. Edison Co. ORNL NS 271 p. Nov. 60 FLD/GP 181 18L.

2. Power Test Program for the La Crosse Boiling Water Reactor, Vol. 1, ACNP-673, Allis-Chalmers A. E. Division. 6935 Arlington Road, Bethesda, Md.

3. R. L. Crowther and L. K. Hollant, Control Management and Automation of the Boiling Water Reactor. Nuclear 69 Basel Switzerland, (1969) General Electric Co., San Jose, Calif.

4. W. B. Morgan, In-Core Neutron Monitoring System for General Electric Boiling Water Reactors, General Electric Company, San Jose, Calif.

5. L. M. Johnson, C. H. Meyer, A Two-range System for Ex-core Neutron Flux Monitoring, Nuclear Power Department, Combusion Engineering, Inc. Windsor, Conn.

6. Current Status and Future Technical and Economic Potential of Light Water Reactors, WASH-1082, (1968) Division of Reactors Dev. Technology, USAEC.

7. H. Pekarek (Electro Watt Enqineering Services, Ltd, Zirich Switzerland) A. F. Veras (Commonwealth Edison Co., Chicago, I11.) The On-line Computer at the Dresden Nuclear Power Station and its Use in Nuclear Fuel Management.

8. R. A. Schneider and D. P. Granquist, Capability of a Typical Material Bälance Accounting System for a Chemical Processing Plany, (July 1969).

9. Evaluation of Fuel Accountability Methods Applied to Yankee Fuel, WCAP-3896-1, (1968).

10. B. I. Spinard, "Predictions of Fuel Burnup for Thermal Reactors," Reactor and Fuel-Processing Technology, Vol. 11, No. 2, (1968).

11. G. C. Andognini, Jr., Procedure to Determine the Thermal Power Level of the Yankee Reactor Core, YAEC 1001, (1961).

12. Dan Curtiss and R. Geronime, An Estimate of Temperature Measurement Errors in a Boiling Water Reactor, AEC Report. No. 16821.

13. Hans K. Fauske, Compressibility Affects Flow Instability and Burnout. Power Reactor Technology, Vol. 9, No. 21, (1966).

14. G. F. Poppen, Measurina Neutron-Flux Distribution in Operatina Reactors, Power Reactor Technology Vol. 9, (1965-1966). 


\section{BIBLIOGRAPHY (CONTD.)}

15. J. Czaika, and W. Kerr, The Use of a Gamma Sensitive Detector to Measure Thermal Reactor Power, IEEE Transaction on Nuclear Science, Vol. NS-16, No. 1, Feb. 1969.

16. H. P. Spracklen, $N^{16}$ Power Control System of the Livermore Pool Type Reactor, IEEE Transactions on Nuclear Science, Vol. NS-14 No. 1, (1967).

17. P. F. Rago, W. Goldstein, E. Tochinlin, Reactor Neutron Measurements with Fission Foil-Lexan Detectors, Nuclear Applications and Technology Vol. 8, Mar. 1970.

18. J. J. Loving, R. J. Nath, Reactor Core Measurements at Connecticut Yankee and Zonita, IEEE Transactions on Nuclear Science, Vol. NS-17, No. 1, (1970).

19. C. R. Wylie, Jr., Advanced Engineering, McGraw-Hill (1960). 
No. of

Copies

OFFSITE

1

5

202

115

20

2

10

1

1

1

5
AEC Chicago Patent Group

G. H. Lee

AEC Division of Nuclear Materials Safeguards

R. G. Page

AEC Division of Technical Information Extension

AEC Office of Safequards and Materials Management

G. M. Inman (75)

S. C. T. McDowe11 (30)

J. M. Williams (20)

Argonne National Laboratory

M. A. Kanter

Arms Control and Disarmament Agency

L. Stieff

Brookhaven National Laboratory

H. Kouts

Idaho Nuclear Corporation

F. H. Tingey

Lawrence Radiation Laboratory, Livermore

R. E. Batzel

Los Alamos Scientific Laboratory

Jane H. Hall

National Bureau of Standards

G. Penn 
No. of

Copies

2

Stanford Research Institute

E. M. Kinderman

ONSITE-HANFORD

1 AEC Chicago Patent Group

R. MI. Poteat (Richland)

3

AEC Richland Operations Office

M. R. Schneller

3 Battelle Memorial Institute

2 RDT Assistant Director for Pacific Northwest Programs

T. liemzek

$40 \quad$ Battelle-Northwest

C. A. Bennett

N. E. Carter

D. E. Christensen

R. G. Clark

D. P. Granquist

L. C. Schmid

R. A. Schneider (20)

R. I. Smith

H. J. Svoboda

V. O. Uotinen

W. C. Wolkanhauer (5)

Technical Information Files (5)

Technical Publications 